\title{
Emergence of Anthelmintic Resistance in Haemonchus contortus on Organized Sheep and Goat Farms of Sub-Himalayan Region of Northern India
}

\author{
Rajeev Ranjan Kumar*, C.L. Yadav and Stuti Vatsya \\ College of Veterinary and Animal Sciences, G.B. Pant University of Agriculture and \\ Technology, Pantnagar-263145, Uttarakhand, India \\ *Corresponding author
}

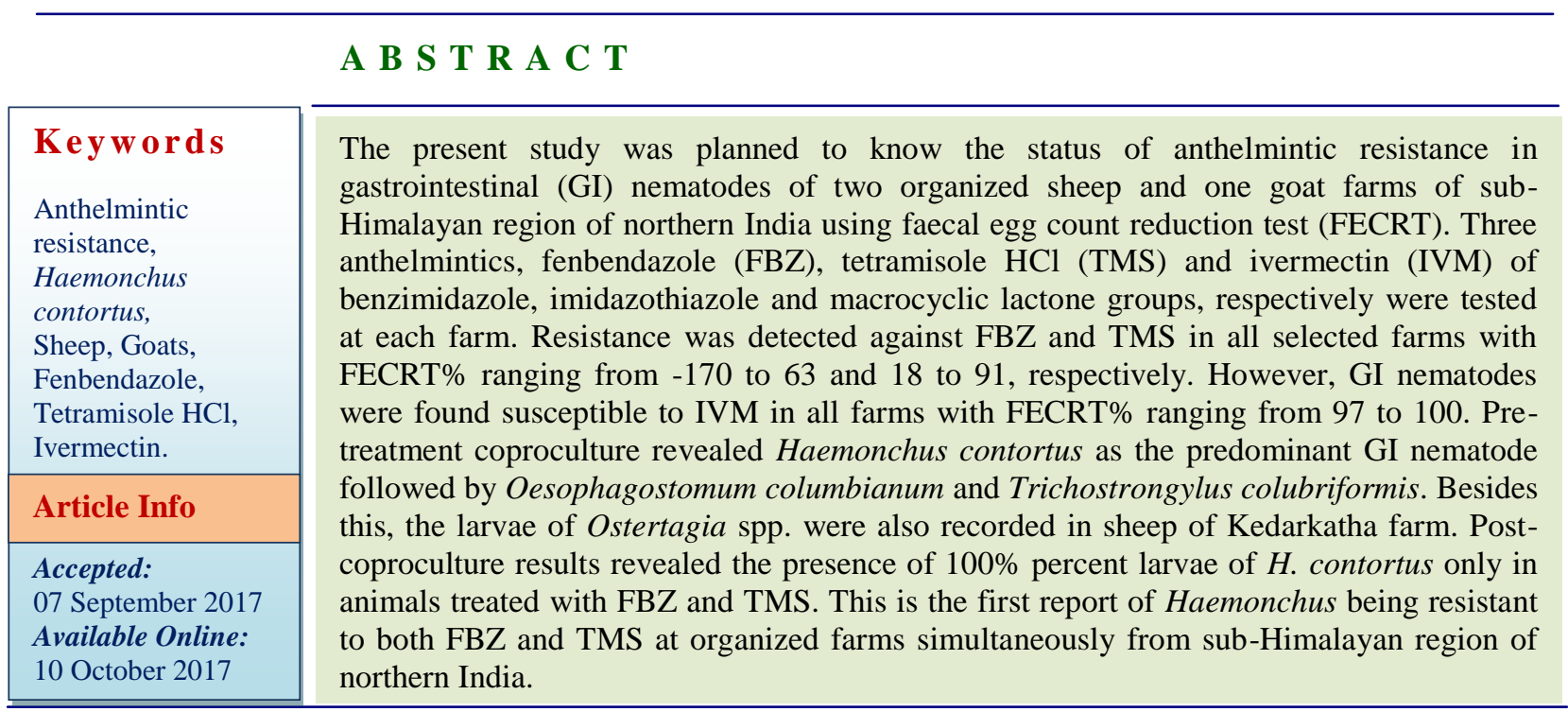

\section{Introduction}

In India, small ruminants contribute in providing economic security to small, landless and marginal farmers. Parasitic diseases are important cause of production losses in small ruminants the world over. Of these, gastrointestinal (GI) nematodosis is a common parasitic infection of small ruminants in India including sub-Himalyan region of northern India (Yadav et al., 2009). It is caused by mixed infections of GI nematodes. Among the various GI nematodes, Haemonchus contortus is the predominant parasite found throughout the year and is considered as the most pathogenic GI nematode responsible for impaired productivity in small ruminants throughout the world (Khalafalla et al., 2011).

Anthelmintics are administered to animals even when they show non-specific clinical signs like diarhhoea or are found positive on faecal examination without estimation of intensity of infection. This has led to indiscriminate and frequent use of the drugs resulting in the emergence of drug resistance (Barton, 1980). Efficacy of various 
anthelmintics must be monitored regularly so that proper selection of anthelmintic can be done otherwise there will be huge economic losses due to cost of anthelmintics, sustained parasitic load due to ineffective worm control strategies and increased selection of resistant worms. The growing importance of these anthelmintic-resistant nematodes and the need for reliable information on their occurrence and spread has increased to rule out their occurrence in a proper area.

In India, the first report of anthelmintic resistance in $H$. contortus to phenothiazine and thiabendazole has been reported by Varshney and Singh (1976) in sheep from Central Sheep and Wool Research Station, Pashulok, Rhikish, Uttar Pradesh (now in Uttarakhand). Then after, various reports on emergence of anthelmintic resistance have been documented from different parts of India (Yadav, 1990; Laha et al., 1999; Garg et al., 2007; Jaiswal et al., 2013; Rialch et al., 2013; Pandey and Vatsya, 2013). However, there is scanty information on the prevalence of anthelmintic resistance from organized sheep and goat farms of sub-Himalayan region of northern India. So, the present study was planned with the objective to know the status of anthelmintic resistance against GI nematodosis at two organized sheep and one goat farms of sub-Himalayan region of northern India.

\section{Materials and Methods}

\section{Location of study area}

The study was carried out at two organized sheep and one organized goat farms located in sub-Himalayan region of northern India. Among the two sheep farms, one organized sheep farm was located at Kedarkatha (1,293 $\mathrm{m}$ above sea level), Chamoli district and the second one was situated at Samaliti $(1,004 \mathrm{~m}$ above sea level), Bageshwar district.
However, goat breeding farm selected in the study was located at Gwaldam $(1,940 \mathrm{~m}$ above sea level), Chamoli district of Garhwal region. Each farm had its own pasture land on which the animals were grazed from early morning till late evening. All animals were dewormed 6-8 times in a year. Fenbendazole and tetramisole $\mathrm{Hcl}$ had been used for 8-10 years.

\section{Selection of animals}

Faecal samples from both sheep and goats of individual farms were collected and examined by modified Mc Master egg counting technique. Animals of the individual farm having faecal egg count more than 200 e. p. g. were included in the present study. The animal flocks selected were not administered any kind of anthelmintic treatment for last three months.

\section{Anthelmintic treatment of animals}

Sixty sheep and forty goats of either sex, aged between 1-3 years and naturally infected with mixed infections of gastrointestinal nematodes (GIN) at each farm were selected, numbered and weighed. The selected sheep were randomly divided into four groups viz. GI, GII, GIII and GIV of 15 animals each. However, goats were randomly divided into four groups viz. GI, GII, GIII and GIV of 10 animals each.

Three anthelmintics of three different classes viz. Benzimidazole (fenbendazole), imidazothiazole (tetramisole $\mathrm{Hcl}$ ) and macrocyclic lactone (ivermectin) were tested in animals of each farm. Animals of GI, GII and GIII groups were treated with commercially available fenbendazole (FentasIntas Pharmaceuticls Ltd. Ahmedabad) @ 5 $\mathrm{mg} / \mathrm{kg}$ body wt. orally (sheep) and @ 10 $\mathrm{mg} / \mathrm{kg}$ body wt. orally (goats), tetramisole hydrochloride (Nilverm-Virbac Animal 
Health India Pvt. Ltd., Mumbai) @ 15 mg/kg body wt. orally and ivermectin (NeomacIntas Pharmaceuticls Ltd. Ahmedabad) @ 0.2 mg/ kg body wt. sub-cutaneously (s/c), respectively. GIV animals were kept as untreated infected control.

\section{Faecal Egg Count Reduction Test (FECRT)}

Faecal samples of each animal of treated and untreated groups were collected directly from rectum in separate polythene faecal bag on day 0 and 10 days post-treatment (DPT).

All the collected samples were kept in ice bag and brought to the laboratory and processed for the estimation of egg per gram of faeces (e.p.g.) using modified Mc Master technique (Coles et al., 1992).

\section{Coproculture and larval identification}

Pooled faecal samples of each group of an individual farm were cultured for speciation of nematodes on day 0 of treatment and on 10 DPT. GI nematode larvae were identified on the basis of their morphological characters as described by Soulsby (1965).

\section{Statistical analysis}

The percent reduction in faecal egg counts was determined as per the guidelines of World Association for the Advancement of Parasitology. Data was also analysed for the calculation of variance of counts $(\mathrm{S})$, variance of reduction and 95\% upper and lower confidence limit (Coles et al., 1992).

Arithmetic mean $\left(\mathrm{X}=\sum \mathrm{X} / \mathrm{N}\right)$ for post treatment FEC

Variance of count $\left[S^{2}=\left\{X^{2}\left(\sum X\right)^{2} / N\right\} N-1\right]$

\% FECR $[100\{1-\mathrm{Xt} / \mathrm{Xc}\}]$
Variance of reduction on $\log$ scale $\mathrm{Y}^{2}=\mathrm{S}_{\mathrm{t}}{ }^{2} /$ $\mathrm{N}_{\mathrm{t}} \mathrm{X}_{\mathrm{t}}^{2}+\mathrm{S}_{\mathrm{c}}^{2} / \mathrm{N}_{\mathrm{c}} \mathrm{X}_{\mathrm{c}}^{2}$

Calculation of $95 \%$ confidence limits-

Upper confidence limit $100\left[1-\mathrm{Xt} / \mathrm{Xc} \operatorname{exp(-2.048}^{\operatorname{en}}\right.$ $\left.\mathrm{Y}^{2)}\right]$

Lower confidence limits100 [1-Xt/Xc $\operatorname{exp(+2.048}$ ${ }^{\text {ó }}{ }^{2)}$ ]

Where $X_{t}=$ arithmetic mean epg count of treated groups, $X_{c}=$ arithmetic mean epg count of control group, $\mathrm{S}_{\mathrm{t}}{ }^{2}=$ variance of treated group, $\mathrm{S}_{\mathrm{c}}{ }^{2}=$ variance of control group, $\mathrm{N}_{\mathrm{t}}=$ number of animals in treated group and $\mathrm{N}_{\mathrm{c}}=$ number of animals in control group .

\section{Interpretation of data}

In FECRT, anthelmintic resistance was confirmed, if (i) the percent reduction in epg count was less than $95 \%$ and (ii) the lower 95 $\%$ confidence interval was less than $90 \%$. If only one of the two criteria was met, the resistance was suspected.

\section{Results and Discussion}

The results of faecal egg count reduction test and confidence limit of the present study are presented in Table 1. The animals of GI, GII and GIII of each farm were treated with FBZ, TMS and IVM, respectively. In animals of GI, GII and GIII at Shamaliti sheep breeding farm, the percentage reduction in FEC recorded was $-170,18$ and 97 with a lower $95 \%$ CI of 0,0 and 93 , respectively. However, the percentage reduction in FEC of $-10,24$ and 100 with a lower $95 \% 0,0$ and 100 , respectively was recorded in animals of GI, GII and GIII at Kedarkatha sheep breeding farm. While, the percentage reduction in FEC of 63, 91 and 100 with a lower $95 \%$ CI of 27, 82 and 99 was recorded in animals of GI, GII and GIII, respectively. 
The coproculture and larval composition of each farm are presented in Table 2. In all selected organized sheep and goats farms, larval composition on pretreatment coproculture examination revealed $H$. contortus as predominant GI nematode (68$82 \%$ ) followed by $O$. columbianum (11-20\%) and $T$. colubriformis (5-15\%). Besides this, the larvae of Ostertagia spp. (2-7\%) were also recorded in sheep of Kedarkatha farm. In all treated animals, hundred percent larvae of $H$. contortus only were observed on 10DPT at each farm.

Based on FECRT data, fenbendazole and tetramisole resistance was observed at all the tested farms. However, GI nematodes in both sheep and goats of the farms were found susceptible to ivermectin. The results of post coproculture examination confirmed that $H$. contortus was resistant to drugs of benzimidazole and imidazothiazole groups in all selected organized sheep and goat farms.

In the present study, the percentage reduction in FEC in FBZ and TMS treated animals were less than $95 \%$ and lower $95 \%$ confidence levels in treated animals were less than $90 \%$.

The post-treatment coproculture examination revealed the presence of only $H$. contortus third stage larvae. It was indicated that the strain of $H$. contortus was resistant to FBZ (benzimidazoles) and TMS (imidazothiazole). This is the first report of $H$. contortus being resistant to both FBZ and TMS at organized farms simultaneously from this part of India.

Animals of each farm were treated with FBZ and TMS since last 8-10 years and also received these drugs 6-8 times in a year. FBZ resistant $H$. contortus in small ruminants has also been reported by various workers from different parts of India (Yadav, 1990; Yadav et al., 1996; Singh and Yadav, 1997; Swarnkar et al., 1999; Swarnkar and Singh,
2012). Benzimidazole resistant $H$. contortus in field flocks of sheep and goats of subHimalayan region of northern India has also been reported by Laha et al., (1999) and Rialch et al., (2013). TMS resistant $H$. contortus has also been reported by Makvana and Singh (2009), Maharshi et al., (2011) and Swarnkar and Singh (2012) from India. The prevalence of FBZ and TMS resistance might be due to frequent use of same anthelmintic for a long period (Maingi et al., 1996). In India, this type of resistant $H$. contortus associated with frequent use of different anthelmintics has also been reported by Uppal et al., (1992), Yadav and Uppal (1993) and Garg et al., (2007).

IVM was found highly effective against mixed infections of GI nematodes at each farm with \% FECR ranging from 97 to 100 . Similar observation has also been reported by Uppal et al., (1992), Laha et al., (1999) and Garg et al., (2007). However, Makvana and Singh (2009) and Jaiswal et al., (2013) observed ivermectin resistant gastrointestinal nematodes in sheep and goats, respectively from Gujrat and Uttar Pradesh, India, respectively. The susceptibility of IVM in the selected farms might be due to less frequent use of IVM in routine deworming programme.

To avoid the failure of anthelmintic treatment in animals of these farms, it is also suggested that veterinarians of the respective farms should perform FECRT\% test to check whether the drugs being used are effective.

Generally farmers or veterinarians treat the animals without accurate weighing resulting into under dosing of the drug. It can be easily avoided by taking the weight of heaviest animals of the flock and then calculate the dose of the drug for all the animals of the flock. 
Table.1 Mean of faecal egg count, percent faecal egg count reduction, variance of count, 95\% confidence limits in animals treated with different anthelmintics at various sheep and goat farms

\begin{tabular}{|c|c|c|c|c|c|c|c|c|}
\hline \multirow[t]{2}{*}{ Name of the farms } & \multirow[t]{2}{*}{ Groups } & \multicolumn{2}{|c|}{ Arithmetic mean } & \multirow[t]{2}{*}{ \% FECR } & \multirow{2}{*}{$\begin{array}{c}\text { Variance of } \\
\text { counts }\end{array}$} & \multicolumn{2}{|c|}{$95 \%$ confidence interval } & \multirow{2}{*}{$\begin{array}{l}\text { Interpretation } \\
\text { of data }\end{array}$} \\
\hline & & Day 0 & 10DPT & & & Upper limit & Lower limit & \\
\hline \multirow{4}{*}{ Shamaliti sheep farm } & GI & 1940 & 2967 & -170 & 7139167 & -27 & 0 & Resistance \\
\hline & GII & 910 & 897 & 18 & 1035524 & 65 & 0 & Resistance \\
\hline & GIII & 1290 & 30 & 97 & 1357 & 99 & 93 & Susceptible \\
\hline & GIV & 906 & 1100 & - & 1362500 & - & - & No significance \\
\hline \multirow{4}{*}{ Kedarkatha sheep farm } & GI & 380 & 497 & -10 & 90524 & 39 & 0 & Resistance \\
\hline & GII & 317 & 343 & 24 & 81381 & 61 & 0 & Resistance \\
\hline & GIII & 460 & 0 & 100 & 0 & - & 100 & Susceptible \\
\hline & GIV & 300 & 450 & - & 169643 & 39 & 0 & No significance \\
\hline \multirow{4}{*}{ Gwaldam goat farm } & GI & 1745 & 1175 & 63 & 934028 & 81 & 27 & Resistance \\
\hline & GII & 3150 & 285 & 91 & 54472 & 94 & 82 & Resistance \\
\hline & GIII & 2785 & 10 & 100 & 0 & 100 & 99 & Susceptible \\
\hline & GIV & 2915 & 3135 & - & 3261139 & & & No significance \\
\hline
\end{tabular}

Table.2 Coproculture examination of animals treated with various anthelmintics at different organized sheep and goat farms

\begin{tabular}{|c|c|c|c|c|c|c|c|c|c|}
\hline Animals (Name of farms) & \multirow[t]{3}{*}{ Groups } & \multicolumn{8}{|c|}{ Percent larval composition } \\
\hline \multirow{6}{*}{ Shamaliti sheep farm } & & \multicolumn{4}{|c|}{ Pre-treatment (0 day) } & \multicolumn{4}{|c|}{10 days post treatment (10DPT) } \\
\hline & & $\mathbf{H}$ & Oe. & $\mathbf{T}$ & $\mathbf{O}$ & $\mathbf{H}$ & Oe. & $\mathbf{T}$ & $\mathbf{O}$ \\
\hline & GI & 70 & 20 & 10 & 0 & 100 & 0 & 0 & 0 \\
\hline & GII & 65 & 20 & 15 & 0 & 100 & 0 & 0 & 0 \\
\hline & GIII & 82 & 10 & 8 & 0 & 100 & 0 & 0 & 0 \\
\hline & GIV & 75 & 20 & 5 & 0 & 76 & 19 & 5 & 0 \\
\hline \multirow{4}{*}{ Kedarkatha sheep farm } & GI & 78 & 12 & 8 & 2 & 100 & 0 & 0 & 0 \\
\hline & GII & 70 & 15 & 10 & 5 & 100 & 0 & 0 & 0 \\
\hline & GIII & 73 & 17 & 6 & 4 & 100 & 0 & 0 & 0 \\
\hline & GIV & 70 & 14 & 9 & 7 & 68 & 15 & 10 & 7 \\
\hline \multirow{4}{*}{ Gwaldum Goat farm } & GI & 68 & 17 & 15 & 0 & 100 & 0 & 0 & 0 \\
\hline & GII & 76 & 14 & 10 & 0 & 100 & 0 & 0 & 0 \\
\hline & GIII & 84 & 11 & 5 & 0 & 100 & 0 & 0 & 0 \\
\hline & GIV & 81 & 13 & 6 & 0 & 80 & 15 & 5 & 0 \\
\hline
\end{tabular}

H-Haemoncus contortus, Oe.-Oesophagostomum columbianum, T-Trichostrongylus colubriformis, O-Ostertagia spp. 
Based on findings of the present study, it is suggested that FBZ and TMS cannot be used to control GI nematodosis in sheep and goats at the selected farms and it may be minimized either by the use of other effective anthelmintic or formulate another effective control strategies against GI nematodes.

\section{Acknowledgements}

Director Research, Experiment Station and Dean, College of Veterinary and Animal Sciences, G. B. Pant University of Agriculture and Technology, Pantnagar are also acknowledged for providing necessary facilities during the entire course of the study. Incharges of all the farms are also highly acknowledged for giving permission to carry out the present work.

Authors are highly thankful to Indian Council of Agricultural Research, New Delhi, India for giving sufficient funds to carry out the present research work in the form of "All India Network Progrmme on GI Parasitism (project grant code-137).

\section{References}

Barton, N.J., 1980. Emergence of Haemonchus contortus resistant to thiabendazole. Aust. Vet. J, 56: 46-47.

Coles, G.C., Bauer, C., Borg steede, F.M.A., Geerts; Klei, T.R., Taxlos, M.A. and Waller, P.J., 1992. World Association for the Advancement of Veterinary Parasitology. Methods for the detection of anthelmintic resistance in nematodes of veterinary importance. Vet. Parasitol, 44: 35-44.

Garg, R., and Yadav, C.L., 2009. Genotyping of Benzimidazole susceptible and resistant alleles in different populations of Haemonchus contortus from Himalayan and sub-Himalayan regions of North-west India. Trop. Anim. Hlth.
Prod, 41: 1127-1131.

Garg, R., Kumar, R.R., Yadav, C.L. and Banerjee, P.S., 2007. Duration of anthelmintic effect of three formulations of ivermectin (oral. Injectable and pouron) against multiple anthelmintic resistant Haemonchus contortus in sheep. Vet. Res. Communic, 31:749755.

Jaiswal, A.K., Sudan, V., Shanker, D. and Kumar, P., 2013. Emergence of ivermectin resistance in gastrointestinal nematodes of goats in a semi-organized farm of Mathura district-India. Veterinarski Arhiv, 83: 275-280.

Khalafalla, R.E., Elseify, M.A. and Elbahy, N.M., 2011. Seasonal prevalence of gastrointestinal nematode parasites of sheep in northern region of Nile Delta, Egypt. Parastol. Res., 108: 337-340.

Laha, R., Hemaprasanth and Harbola, P.C., 1999. Anthelmintic resistance in Pashmina (Cashmere) producing goats in India. Vet. Res. Communic, 23: 187189.

Maharshi, A.K., Swarankar, C.P., Singh, D., Manohar, G.S. and Ayub, M., 2011. Status of anthelmintic resistance in gastrointestinal nematodes of sheep in Rajasthan. Ind. J. Anim. Sci, 81:105109.

Maingi, N., Bjorn, H., Thamsborg, S.M., Bogh, H.O. and Nansen, P., 1996. A survey of anthelmintic resistance in nematode parasites of goats in Denmark. Vet. Parasitol, 66: 53-66.

Makvana, V.N., and Singh, V., 2009. Anthelmintic resistance in nematode parasites of sheep at an organized farm in Gujarat. J. Vet. Parasitol, 23: 43-45.

Pandey, N., and Vatsya, S., 2013. Detection of Benzimidazole resistance in Haemonchus contortus populations collected from Uttarakhand using allele specific PCR assay. Ind. J. Anim. Sci, 83: 24-26. 
Rahman, W.A., 1994. Survey for drugresistant trichostrongyle nematodes in ten commercial goat farms in West Malaysia. Trop. Anim. Hlth. Prod, 26: 235-238.

Rialch, A., Vatsya, S. and Kumar, R.R., 2013. Detection of benzimidazole resistance in gastrointestinal nematodes of sheep and goats of sub-Himalyan region of northern India using different test. Vet. Parasitol, 198: 312-318.

Singh, S., and Yadav, C.L., 1997. A survey of anthelmintic resitance by nematodes on three sheep and two goat farms in Hisar (India). Vet. Res. Communic, 21: 447451.

Soulsby, E.J.L., 1965. Text book of Veterinary Clinical Parasitology Vol. I. Helminths. Blackwell Scientific publication, Oxford, Pp. 334-381.

Swarnkar, C.P., and Singh, D., 2012. Seasonal variation in efficacy of anthelmintics and prevalence of anthelmintic resistance in gastrointestinal nematodes of sheep and goats. Ind. J. Anim. Sci, 82: 451-456.

Swarnkar, C.P., Singh, D., Khan, F.A. and Bgagwan, P.S.K., 1999. Multiple anthelmintic resistance in Haemonchus contortus of sheep. Ind. J. Anim. Sci,
69: 547-549.

Uppal, R.P., Yadav, C.L., Godara, P. and Rana, Z.S. 1992. Multiple anthelmintic resistance in a field strain of Haemonchus contortus in goats. Vet. Res. Communic, 16: 195-198.

Varshney, T.R., and Singh, Y.P., 1976. A note on development of anthelmintic resistance of Haemonchus contortus worms against phenothiazine and thiabendazole in sheep. Ind. J. Anim. Sci, 46: 666-668.

Yadav, C.L., 1990. Fenbendazole resistance in Haemonchus contrtus of sheep. Vet. Rec, 126: 586.

Yadav, C.L., and Uppal, R.P., 1993. Resistance of caprine Haemonchus contortus against fenbendazol. Ind. Vet. J, 70: 798-800.

Yadav, C.L., Ghorui, S.K., Singh, B.P. and Sharma, M.C., 1996. Benzimidazole resistance in Haemonchus contortus of sheep and goats in Uttar Pradesh, India. Indian Journal of Vet. Parasitol, 10: 4751

Yadav, C.L., Kumar, R.R., Banerjee, P.S., Godara, R., Garg, R. and Vatsya, S. 2009. Epidemiology of gastrointestinal nematodosis in sheep. Ind. Vet. J, 86: 1010-1013.

\section{How to cite this article:}

Rajeev Ranjan Kumar, C.L. Yadav and Stuti Vatsya. 2017. Emergence of Anthelmintic Resistance in Haemonchus contortus on Organized Sheep and Goat Farms of Sub-Himalayan Region of Northern India. Int.J.Curr.Microbiol.App.Sci. 6(10): 790-796. doi: https://doi.org/10.20546/ijcmas.2017.610.095 